\title{
RELATIONSHIP BETWEEN STOMATAL CONDUCTANCE AND LEAF WATER POTENTIAL IN SELECTED FOREST TREE SPECIES GROWING UNDER DIFFERENT LEVELS OF NATURAL SHADE IN THE MID-COUNTRY WET ZONE
}

\author{
W.A.J. M. DE COSTA *, W.A.M.W.K.S.B ABEYSINGHE and A.G. CHANDRAPALA \\ Department of Crop science, Faculty of Agriculture, University of Peradeniya, Peradeniya
}

(Received: 24 March 1999 ; accepted: 07 February 2000)

\begin{abstract}
Variation of leaf stomatal conductance $(g)$ js one of the mechanisms by which forest plants respond to rapidly-changing environmental conditions. By influencing the turgor pressure of guard cells, leaf water potential ( $\Psi^{\prime}$ ) could be a determinant of $g$. Therefore, the objectives of the present study were: (a) to examine the variation of $g_{3}$ and $\Psi$ in selected forest tree species under varying levels of natura] shade; (h) to quantify the relationship between $g_{1}$ and ' $x^{\prime}$; and thereby (c) to determine the environmental and plant factors t] at determine gr.
\end{abstract}

This study was conducted at the Lower Hantana, university forest site firom September 1998 to January 1999. Nine forest tree species (Alstonia macrophyll.a, Mararanga peltata, Acronychica pedunculata, Tecton a grandis, Terminalia catappa, Sumietenia macrophylla, Filicium decipiens, Mesua ferrea and Semicarpus ni.gro-viridis) which included both pioneer and climax forms, growing under different levels of natural shade, i.e. open, medium shade and full shade, were used for measurements.

Total leaf conductance $(g)$ varied significantly with tree species and shade levels. The highest g, were observed in Seruicurpus and Terminuliu, i.e. 92 and 78 mmol $\mathrm{m}^{-2} \mathrm{~s}^{-1}$ respectively. The rest of the species had significantly lower $\mathrm{g}_{1}$ values,

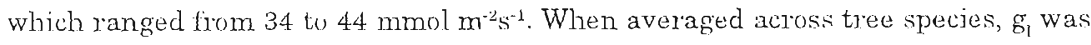
significantly greater under open conditions as compared to medium and full shade. $\Psi$ also varied significantly with tree species and shade levels. The lowest $\Psi^{\prime}$ values were shown by Swietenica and Filicium.

There was a positive relationship hetween ' $\Psi$ ' and $g$ under all three shade levels. However, the relationship was strongest $\left(r^{2}=0.764\right)$ under open conditions and became weaker with increasing shade $\left(r^{2}=0.531\right.$ and 0.363 under medium and full shade respectively). Under open conditions, $58 \%$ of the overall variation of $g_{1}$ was explained by $\Psi$. This decreased to $28 \%$ under medium shade. Under full shade, $93 \%$ of the variation of $g$, was explained by leaf temperature and light intensity. Stomatal density did not have a significant correlation with $g_{1}$ despite showing significant variation with tree species and shade levels.

Key words: Acronychia pechuncullata, Alstonia macrophyll.a, Filicium decipiens, Mac:aranga peltata, Mesua ferrea, Semicarpus nigro-viridis, shade, stomatal conductance, stomatal density, Suietenia macrophyll,a, Terminalia catappa, Tectona grann.dis, water potential.

* Corresponding author 


\section{INTRODUCTION}

The degree of opening of stomata, as measured by the stomatal conductance ${ }^{1.3}$, is a vital parameter that determines the rates of photosynthesis and transpiration by all types of plants including those found in natural forests. ${ }^{4-6} \mathrm{~A}$ characteristic feature of natural forests is the heterogeneity and variability of the environmental conditions experienced by the plants, both spatially and temporally. ${ }^{7}$ The way that different species co-existing within a forest respond to the above variation and heterogeneity of the environment determines their survival and the degree of dominance that they would achieve in the succession process. ${ }^{.}$

Ability of the stomata to respond rapidly to variations in environmenta] factors such as light intensity, temperature, humidity and wind" make them ideal organs through which forest plants respond and adjust their functioning to rapid fluctuations in the environment. This ability is especially crucial for survival and growth of natural forest plant species because key physiological processes such as photosynthesis of these species occur mostly under rapidly-fluctuating transient environmental conditions rather than stable, steady-state conditions. ${ }^{10,11}$

The primary determinant of stomatal movements at the cellular level is the water content of guard cell.s. ${ }^{12.1 .3}$ Guard cell water content is determined by the water status of the leaf which is in turn determined by the transpirational stream through the soil-plant-atmosphere continuum. ${ }^{14}$ Hence, it is hypothesized that leaf water status, measured as the leaf waterpotential ${ }^{15}$, may play a crucial role in determining stomatal conductance in a variable environment.

Therefore, it is important to investigate the environmental factors that determine the stomatal conductance and leaf water potential of different tree species found in natural forests. There is significant inter-species variation in how different plant species respond to even the same perturbatior. i: the external environment. ${ }^{16,17}$ For example, the response to an increase in the incident light intensity may be substantially-positive for stomatal conductance in pioneer and early-successional species. ${ }^{1 *}$ On the other hand, the corresponding response may be insignificant in late-successional and climax species. Therefore, the objectives of the present study were: (a) to determine the variation of stomatal conductance and leaf water potential of different tree species growing under a range of natural shade regimes; (b) to examine the relationships between stomatal conductance and the environmental (i.e. light and temperature) and plant factors (i.e. leaf water potential) that could have an influence on stomatal conductance; and thereby (c) to identify key factors that determine the stomatal conductance of plant species growing in natural forests. 


\section{METHODS AND MATERIALS}

Experimental location: The experiment was conducted at the Lower Hantana university forest site at Peradeniya from August 1998 to January 1999. This semi-natural forest site is located in the mid-country wet zone, $\mathrm{WM}_{2}{ }^{1 .}$, at an elevation of $479.9 \mathrm{~m}$ above mean sea level. The mean annual rainfall is $2000 \mathrm{~mm}$ which is well-distributed throughout the year. ${ }^{19}$ The experimental period coincided with the inter-monsoonal and north-east monsoon rainy season. The mean annual temperature is around $26-28^{\circ} \mathrm{C}$. The soil was well-drained with a mixture of Reddish Brown Latasolic (Rhodudults Mropudults ${ }^{19}$ ) and alluvial soil types.

Tree species and shade levels: The experimental site contained a mixture of tree species at different stages of growth and the canopy cover of the forest floor varied in patches from fully-shaded to completely open. Out of those present, nine tree species were selected to broadly represent pioneer and climax species. Alstonia macrophylla Wall. ex G. Don (Hawarinuga), Macaranga peltata Wight (Kenda), Acronychia pedunculata Miq. (Ankenda), Tectona grandis L. f. (Teak), and Terminalia catcippa L. (Kottamba) were selected as pioneer and early-successional tree species. Stuietenia macrophylla King (Mahogany), Filicium decipicns Thw. (Pihimbiya), Mesuc ferrea Auct. (non L.) (Na) and Semicarpus nigro-viridis Thw. (Badulla) were selected as late-successional and climax species.

Six plants from each tree species were selected and tagged for continuous measurements. All plants selected were at the sapling stage. These six plants were selected to represent three levels of natural shade at which they were growing. These natural shade levels were defined on the basis of the percentage of maximum incident radiation received at mid-day measured using a pair of tube solarimeters. ${ }^{20}$ The three shade levels were defined as: open $(80-100 \%$ of incident radiation received on the forest floor); medium shade $(30-80 \%)$ and full shade $(<30 \%)$. Radiation measurements, to define the shade regimes, were done over a continuous period of five days before the experiment was properly begun. The maximum recorded levels of incident radiation ranged from 1030 to $1260 \mu \mathrm{mol} \mathrm{m} \mathrm{m}^{-2} \mathrm{~s}^{-1}$ of photosyntheticallyactive radiation (PAR) during the mid-day. The six replicate plants from each tree species were selected so that there were two replicate plants at each shading level. All plants selected for measurement were at the sapling or seedling stage. Within each tree species, plants at approximately similar growth stage were selected.

Measurements: Measurements started on 26 August 1998 and continued up to 7 January 1999 at fortnightly intervals. On each day, the following variables were measured.

Leaf stomatal conductance $\left(\mathrm{g}_{1}\right)$ : Stomatal conductaince was measured at fortnightly intervals using an automatic Diffusion Porometer (Model APIII, Delta-T Devices, Cambridge, UK). All measurements were taken during the three-hour period between 
1100 and 1400 hours. From each plant, two duplicate measurements were taken on fully-expanded young leaves. The porometer was calibrated at the beginning of each day of measurement. Upper and lower leaf surface conductances were measured separately. Leaf temperatures and incident radiation intensity on the respective leaf surfaces were measured simultaneously with a temperature sensor and a silicon quantum sens or located in the porometer cup. Total leaf conductance was calculated by summing the upper-and lower-surface conductances. Tree species which did not have stomata on the upper leaf surface recorded a very small (usually less than 5 mmol $\mathrm{m}^{-2} \mathrm{~s}^{-1}$ ) value of upper-surface leaf conductance. This is because of the small amounts of transpiration that occur through the cuticle.

Leaf water potential ( $\Psi$ ): Measurements of $g_{1}$ and $\Psi$ of each selected plant were carried out simultaneously. Leaf water potential was measured during daytime using the pressure chamber technique. ${ }^{21}$ Leaves on which $g$, was measured were immediately used for measurement of $\Psi$. Leaves were excised with a smooth, clean cut using a sharp razor blade and $\Psi$ was measured immediately afterwards, thus minimizing errors due to transpirational losses. Increase of pressure within the chamber was done very slowly and the end point (j.e. the point at which the first water bubble appeared on the cut surface) was observed carefully with a hand lens.

Stomatal density on the lower surface: Stomatal density (i.e. number of stomata per unit leaf area) was counted on peeled epidermal strips under 10 × 40 magnification of the light microscope. From each plant, three replicate leaves were used for obtaining epidermal strips. Initially examination of epidermal strips showed that the stomata are predominantly located on the lower surface. Therefore, only the lower leaf surface was used for detailed counting of stomata. Epidermal strips were obtained only from middle part of the blade of healthy, fully-expanded leaves. Stomatal density, instead of stomatal index, was measured because of two reasons. Firstly, it was needed to verify whether the leaf stomatal conductance, which is measured in terms of unit leaf area, is correlated to the number of stomata present per unit leaf area. Secondly, stomatal density may be an indication of the potential transpiration capacity of a given tree species.

Data analysis: Significance of the effects of different tree species and shade levels on total leaf conductance $\left(g_{l}\right)$ and $\Psi$ were tested using analysis of variance (ANOVA) and least significant difference (LSD). ${ }^{22}$ Data taken on different days of measurement were analyzed together with day of measurement included in the ANOVA table as a source of variation.

Strength of the association between $g_{1}$ and measured leaf and environmental variables (i.e. $\Psi$, incident light intensity and leaf temperature) was estimated by multiple correlation analysis. ${ }^{2: 3}$ Correlation analysis was first performed for the whole data set which included all tree species and shade levels. Subsequently, separate correlation analyses were done for the three shade levels. 
Contributions of the leaf and environmental variables to the variation of $\mathrm{g}_{\mathrm{i}}$ were estimated by multiple regression analysis ${ }^{22}$ using the stepwise procedure. The full model for the multiple regression was:

$$
g_{1}=a+b L_{1}+c L_{u}+d T_{1}+e T_{u}+f \Psi+\text { error }
$$

where $\mathrm{L}$ and $\mathrm{T}$ were incident light intensity and leaf temperature with subscripts $l$ and u denoting upper and lower leaf s:urfares.

The extent to which stomatal density influenced the determination of stomatal conductance was estimated by performing a simple correlation analysis between stomatal conductance and stomatal density. Correlation analysis was first done for the overall, pooled data set and thereafter for different shade levels separately.

\section{RESULTS}

In the analysis of variance of stomatal conductance $\left(\mathrm{g}_{1}\right)$ and leaf water potential ( $\Psi$ ), the observed values of $g_{1}$ and $\Psi$ did not differ significantly $(p<0.05)$ between different days of measurement. Moreover, the days of measurement did not have a significant $(p<0.05)$ interaction with the other two main effects of the ANOVA (i.e. tree species and shade levels). Therefore, measurements of $g_{1}$ and $\Psi$ obtained at fortnightly intervals were pooled to obtain mean values. Effects of tree species, shade levels and tree species $\mathrm{x}$ shade interaction on such pooled values $g_{j}$ and $\Psi$ are described below.

Total leaf stomatal conductance $\left(g_{1}\right)$ : Analysis of variance showed that $g_{1}$ (i.e. sum of lower and upper surface conductances) varied significantly with tree species $(p=0.0001)$ and shade level $(p=0.0008)$. In addition, there was a significant species $x$ shade interaction $(p=0.0003)$. Among the tree species tested, Semicarpus and Terminalia had the highest mean $\mathrm{g}_{1}$ which were 92 and $78 \mathrm{mmol} \mathrm{m} \mathrm{m}^{-2} \mathrm{~s}^{-1}$ respectively (Table 1 ). The rest of the species had significantly lower mean $g_{1}$ values which ranged from 34 to $44 \mathrm{mmol} \mathrm{m}^{-2} \mathrm{~s}^{-1}$. When averaged across tree species, mean g) was significantly greater in the open conditions (Table 1). There was no significant difference between $g_{1}$ under medium and full shade conditions.

Because of the significant species $x$ shade level interaction, the variation of $g$ of different tree species has to be examined at different levels of shading. Similar to the trend shown for the overall mean, Semicarpus and Terminalia had the highest $\mathrm{g}$; under open conditions (Table 1). However, in addition, Mesua and Alstonia also had higher values of $g_{1}$ under open conditions. The lowest $g_{1}$ values under open conditions were shown by Filicium and Swietenia. 
Semicarpus and Terminalia had significantly greater $g_{1}$ under fully-shaded conditions as well (Table 1). The rest of the tree species had significantly lower $g_{1}$ values with the lowest being shown by Mesua and Acronychia. Under medium shade, several species had higher g, values (Table 1). These included Terminalia, Swietenia, Filicium and Semicarpus. On the other hand, the lowest $\mathrm{g}_{1}$ under medium shade was shown by Macaranga and Tectona.

ANOVA can also be used to examine the response of $g_{1}$ in individual tree species to variation in shade (Table 1). Alstonia, Macaranga, Mesua and Tectona had significantly greater g, under open conditions. Semicarpus and Terminalia had their highest $g_{1}$ under full shade. However, both these species had higher $g_{1}$ values under open conditions as well. Filicium and Swietenia had their highest $\mathrm{g}_{1}$ under medium shade. Although Acronychia also had its highest $g_{1}$ under medium shade, this value was not significantly different (at $p=0.05$ ) from its corresponding value under open conditions.

Table 1: Variation of stomatal conductance $\left(\mathrm{mmol} \mathrm{m}^{-2} \mathrm{~s}^{-1}\right)$ of different tree species under varying levels of natural shade

Shade levé?

\begin{tabular}{lllll} 
Tree species & Open & Medium & Full & Mean \\
\cline { 2 - 5 } Alstonia macrophylla & 63.64 & 34.69 & 32.25 & 43.45 \\
Filicium decipiens & 35.60 & 57.65 & 19.16 & 37.47 \\
Macaranga peltata & 52.05 & 14.97 & 36.20 & 34.41 \\
Tectona grandis & 51.50 & 25.25 & 25.90 & 34.22 \\
Acronychia pedunculata & 46.32 & 49.30 & 15.98 & 37.20 \\
Semicarpus nigro-viridis & 96.80 & 53.55 & 125.75 & 92.03 \\
Swietcria macrophylla & 41.25 & 60.00 & 29.35 & 43.54 \\
Mesua ferrea & 76.00 & 36.55 & 6.86 & 39.80 \\
Terminalia catappa & 82.75 & 64.05 & 87.75 & 78.18 \\
\hline Mean & 60.66 & 44.00 & 42.13 & \\
\hline
\end{tabular}

LSD (species comparison $)=16.63$

$\operatorname{LSD}_{(0.0): 1}^{0.0 \% 5}$ (shade level comparison $)=9.60$

Leaf water potential $(\Psi)$ : Leaf water potential also varied significantly with tree species $(p=0.0001)$ and shade levels $(p=0.0001)$ Besides, the species $x$ shade interaction was also significant $(p=0.0001)$. When averaged across different shade levels, Swietenia and Filicium showed the lowest $\Psi$ (Table 2). Acronychia and Tectona. also had lower $\Psi$ which were not significantly different $(p<0.05)$ from those of Swietenia and Filicium. The highest overall $\Psi$ were shown by the group of tree 
species which included Mesua, Terminalia and Macaranga. Semicarpus and Alstonia had $\Psi$ values which were slightly, but significantly $(\mathrm{p}<0.05)$ lower than the above species group.

Because of the significant species $\mathrm{x}$ shade interaction, inter-species variation in $\Psi$ has to be examined separately at different shade levels. The inter-species variation of $\Psi$ under open and medium shade conditions showed a pattern which was mostly similar to the overall pattern described above (Table 2). The comparative variation of $\Psi$ between different, species changed sljghtly under full shade. Several tree species showed their lowest $\Psi$ under full shade (Table 2). These included Filicium, Swietenia, Mesua, Tectona and Terminalia. Macaranga was the only species which showed its lowest $\Psi$ under open conditions. Meanwhile, Alstonia showed its lowest $\Psi$ under medium shade. However, this value did not differ significantly $(p<0.05)$ from $\Psi$ of Alstonia under open conditions (Table 2 ) which was only slightly higher. In Acronychia, $\Psi$ did not differ significantly $(p<0.05)$ between different shade levels. In Semicarpus, $\Psi$ under medium shade was significantly greater than its corresponding $\Psi$ values under both open and full shade conditions. It was these varied responses of $\Psi$ in different tree species to varying shade conditions that created the significant species $x$ shade interaction.

Table 2: Variation of leaf water potential (bars) of different tree species under varying levels of natural shade

Shade level

\begin{tabular}{lcccr} 
Tree species & Open & Medium & Full & Mean \\
\cline { 2 - 5 } Alstonia macrophylla & -6.15 & -6.40 & -5.45 & -6.00 \\
Filicium decipiens & -12.75 & -13.30 & -15.90 & -13.98 \\
Macaranga peltata & -5.95 & -5.30 & -4.80 & -5.35 \\
Tectona grandis & -9.65 & -5.35 & -15.00 & -10.00 \\
Acronychia pedunculata & -10.00 & -10.35 & -10.05 & -10.13 \\
Semicarpus nigro-viridis & -6.90 & -5.75 & -7.00 & -6.55 \\
Sivietenia macrophylla & -12.55 & -13.30 & -16.40 & -14.08 \\
Mesua ferrea & -4.40 & -4.80 & -6.75 & -5.32 \\
Terminalia catappa & -4.90 & -5.10 & -6.05 & -5.35 \\
\hline Mean & -8.14 & -7.74 & -9.71 & \\
\hline
\end{tabular}

LSD (species comparison) $=1.07$

$\operatorname{LSD}_{(1,1) ;}^{(1): 5}$ (shade level comparison) $=0.62$ 
Table 2 also showed that the variation of $\Psi$ between tree species was greater than that between different shade levels. This is shown by the nearly four-fold variation in $\Psi$ between species as compared to the narrower variation between shade levels.

Relationship between stomatal conductance and leaf water potential: When all tree species and shade levels were taken together, $\mathrm{g}_{1}$ showed a weak positive correlation $\left(r^{2}=0.250\right)$ with $\Psi$ (Table 3 ). This meant that when $\Psi$ is lower, g, was also lower and vice versa. For example, Terminalia showed higher values of both $g_{1}$ and $\Psi$ '. At the other end of the scale, Filicium and Tectona had lower levels of both $g_{j}$ and $\Psi$. Likewise, the lowest $g$, and $\Psi$ were shown under full shade.

Table 3: Variation of the correlation coefficient $\left(x^{2}\right)$ between stomatal conductance and leaf water potential of different tree species under varying levels of natural shade.

\begin{tabular}{lcc}
\hline Shade level & $\mathrm{r}^{2}$ & Probability $^{*}$ \\
\hline Open & 0.764 & 0.017 \\
Medium shade & 0.531 & 0.141 \\
Full shade & 0.363 & 0.336 \\
\hline Overall & 0.250 & 0.068 \\
\hline
\end{tabular}

Probahility of obtaining a correlation coefficient as large as or larorer than that given here by chance alones.

However, when the correlation analysis was performed separately for different shade levels, it was observed that the strength of correlations between $g_{1}$ and ' $\Psi$ ' varied for different shade levels (Table 3 ). The strongest correlation between $g_{1}$ and $\Psi^{\prime}$ was found under open conditions $\left(r^{2}=0.764\right)$. The correlation coefficient, which indicated the strength of the relationship between $g_{3}$ and $\Psi$, decreased with increasing shade (Table 3). Physiological implications of this observation are given in the discussion.

\section{Factors determining the variation of stomatal conductance}

Table 4 shows the results of multiple regression analysis using the stepwise procedure on factors determining the variation of $g_{j}$ under different shade levels. Under open conditions, $58 \%$ of the variation of $g$, was explained by the variation of $\Psi$. In contrast, only $28 \%$ of the variation of $g_{1}$ was explained by $\Psi$ under medium shade (Table 4 ). On the other hand, light intensity incident on the upper leaf surface $\left(\mathrm{L}_{\mathrm{u}}\right)$ explained $35 \%$ of the variation of $g_{1}$ under medium shade. Interestingly, when it came to fully shaded conditions, $\Psi$ no longer had a significant influence in determining $g$ (Table 4). The contribution of $\Psi^{\prime}$ to the observed variation of $g_{1}$ in the multiple 
regression model was insignificant. Under full shade, $93 \%$ of the variation of $g_{1}$ was explained by the variation of leaf temperatures on the lower $\left(\mathrm{T}_{1}\right)$ and upper $\left(\mathrm{T}_{\mathrm{u}}\right)$ surfaces and light intensity incident on the upper leaf surface $\left(\mathrm{L}_{\mathrm{v}}\right)$.

Table 4: Factors contributing to the observed variation of stomatal conductance of different tree species at different shade levels

\begin{tabular}{|c|c|c|c|c|}
\hline Shade level & $\begin{array}{l}\text { Variable } \\
\text { estimate }\end{array}$ & Parameter & Partial $R^{2}$ & Probability \\
\hline Open & $\begin{array}{c}\text { Leaf water } \\
\text { potential }(\Psi)\end{array}$ & 4.948 & 0.5841 & 0.0165 \\
\hline \multirow[t]{2}{*}{ Medium } & $\Psi$ & 3.358 & 0.2819 & 0.0323 \\
\hline & $\begin{array}{l}\text { Light intensity } \\
\text { on upper leaf } \\
\text { surface }\left(L_{u}\right)\end{array}$ & 0.143 & 0.3596 & 0.0496 \\
\hline \multirow[t]{3}{*}{ Full } & $\mathrm{L}_{\mathrm{u}}$ & 0.391 & 0.4742 & 0.0098 \\
\hline & $\begin{array}{l}\text { Lower surface } \\
\text { leaf temperature } \\
\qquad\left(\mathrm{T}_{1}\right)\end{array}$ & -38.635 & 0.2757 & 0.0011 \\
\hline & $\begin{array}{c}\text { Upper surface } \\
\text { leaf temperature } \\
\left(\mathrm{T}_{\mathrm{l}}\right)\end{array}$ & 39.116 & 0.1771 & 0.0176 \\
\hline
\end{tabular}

"Probability of obtaining a regression parameter estimate as large as or: larger than that given bere hy chance ajone.

Note: Only those parameter estimates with a prohability value of less than 0.1500 are given. $R^{2}$ values of the full regressions models were ().5841 (open), 0.6415 (Medium shade) and 0.9270 (Full shade).

\section{Stomatal density}

Stomatal density varied significantly for different tree species $(p=0.0001)$ and under different shade levels ( $p=0.04$ ). However, the species $\mathrm{x}$ shade interaction was not significant at $\mathrm{p}=0.05$. Swietenia and Filicium showed significantly greater $(\mathrm{p}<0.05)$ stomatal densities than the rest of the tree species (Table 5). On the other hand, Mesua, Semicarpus and Acronychia had the lowest stomatal densities. Among the tree species which had intermediate values of stomatal densities the species group containing Macaranga, Alstonia and Terminalia had significantly greater stomatal densities than Tectona.

When averaged across species, stomatal density showed a decreasing trend with increasing shade (Table 5). However, within some species, there were slight variations in this trend such as in Alstonia and Tectona where the stomatal density under medium shade was lowest and highest respectively (Table 5). On the other 
hand, Filicium decipiens showed the opposite trend with stomatal density increasing with increasing shade. However, the range of variation of mean stomatal density between different species was much broader (i.e. from 40 to $658 \mathrm{~mm}^{-2}$ ) than the corresponding range for different shade levels (i.e. $231-272 \mathrm{~mm}^{-2}$ ). This was the reason for the lack of statistical significance in the species $\mathrm{x}$ shade interaction.

Table 5: Variation of stomatal density $\left(\mathrm{mm}^{-2}\right)$ of different tree species under varying levels of natural shade

Shade level

Tree species

Shade level

\begin{tabular}{lcccc}
\cline { 2 - 5 } & Open & Medium & Full & Mean \\
\hline Alstonia macrophylla & 394 & 177 & 246 & 273 \\
Filicium decipiens & 328 & 453 & 495 & 425 \\
Macaranga peltata & 330 & 290 & 275 & 299 \\
Tectona grandis & 149 & 165 & 141 & 152 \\
Acronychia pedunculata & 102 & 91 & 97 & 97 \\
Semicarpus nigro-viridis & 79 & 61 & 76 & 72 \\
Swietenia macrophylla & 801 & 718 & 454 & 658 \\
Mesua ferrea & 27 & 48 & 44 & 40 \\
Terminalia catappa & 238 & 264 & 249 & 251 \\
Mean & 272 & 252 & 231 & \\
\hline
\end{tabular}

LSD (species comparison) $=78$

$\mathrm{LSD}_{(0,05}^{(0,05)}($ shade level comparison $)=42$

Table 6: Correlation coefficient $\left(\mathrm{r}^{2}\right)$ between stomatal conductance and stomatal density of different tree species under varying levels of natural shade

\begin{tabular}{lcc}
\hline Shade level & $\mathrm{r}^{2}$ & Probability $^{*}$ \\
\hline Open & -0.507 & 0.163 \\
Medium shade & 0.404 & 0.281 \\
Full shade & -0.197 & 0.611 \\
Overall & 0.075 & 0.711 \\
\hline
\end{tabular}

"Probability of ohtaining a correlation coefficient as large as or larger than that given here by chance alone. 
Correlation analysis showed that stomatal dencity did not have a significant correlation with stomatal conductance (Table 6). This was true when correlation analysis was done for the pooled data set as well as for different shade levels. Inclusion of stomatal density in the multiple regression model did not improve its $\mathrm{R}^{2}$ significantly (data not shown).

\section{DISCUSSION}

Results on the variation of both stomatal conductance and leaf water potential clearly showed that there are significant inherent differences in these physiological properties between tree species at any given shade regime. Although there were inherent inter-species differences in stomatal density as well, results of the present study showed that stomatal density does not play a significant role in determining stomatal conductance. This agreed with the findings of Jones ${ }^{24}$ that, rather than the number of stomata present, the size of stomatal aperture and the degree of its opening are the factors that determine the total stomatal conductance of a leaf.

Inter-species variation in $g_{1}$ showed that within the limited list of species examined in the present study, a clear differentiation in $g_{1}$ could not be identified along the lines of pioneer and climax species. This is because the two species which showed greater levels of $g_{1}$ included both an early-successional species (Terminalia) and a late-successional species (Semicarpus). The observation that these two species were able to maintain higher levels of $g_{1}$ under both open and shaded conditions meant that these species had an inherently greater capacity to facilitate gas exchange irrespective of the shading regime.

On the other hand, $g_{1}$ in the rest of the species did respond to shading by showing the expected decline in $g_{1}$ with increasing shade. Interestingly, within this group also, species differed in the pattern of response to gradual increase of shade with some species such as Filiciurn and Swietenia having greater $g_{1}$ under medium shade. Therefore, even within this limited group, different tree species have different levels of optimum shading/light regimes for maximizing stomatal conductance and thereby gas exchange and photosynthesis. This observation confirms the conclusion by Bazzaz ${ }^{17}$ that different tree species which co-exist in a community respond differently to even the same variation in their external environment.

Leaf water potential $(\Psi)$ is a parameter which indicates the level of water availability within a plant. $\Psi$ is determined by the balance between water uptake through the root system and water loss through transpiration. ${ }^{25}$ For example, the significantly lower levels of $\Psi$ in Swietenia, Filicium and Acronychia (Table 2) may be due to either higher transpiration rates or a lower capacity for water absorption through the root system. Similarly, lower transpiration rates or higher root absorption capacity or both could be the cause( $s$ ) of higher $\Psi$ observed in Mesua and Terminalia. Therefore, the processes of transpiration and water absorption and the environmental 
and plant factors that determine them have to be investigated in detail to identify the exact cause of variation of $\Psi$ in a given species.

The greater range of variation in $\Psi$ between species as compared to the corresponding range between shading levels indicate that $\Psi$ is a relatively stable parameter indicating the status (in terms of water availability) of each species within. a community. This hypothesis is supported by the work of Mitloehner ${ }^{26 i}$ who showed, through detajled measurements in a range of forest types in Africa and South America, that $\Psi$ of different tree species can be used as a criterion for selecting suitable tree species to be planted in sites of varying water availability.

The observation that some tree species had their lowest $\Psi$ under full shade was contrary to the general line of reasoning based on the fact that transpiration should be lower under shade and therefore that $\Psi$ should be higher. However, when plants are growing as a community each individual has to compete with its neighbours for essential resources including water. ${ }^{27}$ Accordingly, the root system of a plant growing under the natural shade of a largar twee, has to compete with the larger and more extensive tree root system to absorb water. It is highly likely that when absorbing water from the same soil profile, more water will be absorbed by the root system of the larger tree than that of the smaller sapling growing under the shade of the tree. This lowered absorption of water could decrease the $\Psi$ of saplings growing under full shade as observed for several species in the present, study.

The most important finding of the present study was the way in which different environmental and plant factors interacted to determine stomatal conductance under different shade levels. The positive correlation between $g_{1}$ and $\Psi$ indicated that $\Psi$ did have a controlling influence on determining g. Greater $\Psi$ ' indicates a higher water balance status in the leaves ${ }^{15}$ and ther efore, a higher turgor pressure in the guard cells which would cause greater stomatal opening. ${ }^{12.1:}$ On the other hand, if there had been a negative correlation between $g_{1}$ and $\Psi$, we could have inferred that $g_{1}$ controlled $\Psi$ rather than vice versa. Then greater stomatal opening could have increased transpiration rates beyond the capacity of the root system to recharge the water lost. This would have decreased $\Psi$ thus showing a negative correlation between $g_{1}$ and $\Psi$.

However, the degree of control exerted by $\Psi$ in determining $g_{1}$ varied with the level of shading (Table 3). The stronger correlation between $g_{1}$ and $\Psi$ under open conditions indicates that $\Psi$ has a greater control over $g_{1}$ undex open conditions as compared to shaded conditions. This may be explained as bejng due to the following phenomena. At the higher light intensities experienced under open conditions, transpiration and photosynthesis of leaves occur at their maximum rates. ${ }^{2 *}$ To maintain these higher rates of transpiration and photosynthesis, stomata have to be kept open (i.e. higher gis ) and this is achieved by maintaining higher water potentials in leaves and higher turgor pressure levels in the guard cells. Moreover, 
a higher $\Psi$ in the leaves increases the water vapour concentration gradient between leaves and the surrounding air ${ }^{2 ! 3}$, thus facilitating higher transpiration rates. Because of these inter-related processes, there is a strong positive correlation between $g_{1}$ and w under open conditions.

On the other hand, the decreasing strength of correlation between $g$, and $\Psi$ meant that the role of $\Psi$ in determining $g_{1}$ becomes less important with increasing shade. This was because factors other than $Y^{\prime}$ become more dominant than $\Psi$ in determining $g_{1}$ under shaded conditions. This hypothesis was confirmed by the results of the multiple regression analysis (Table 4) which identified factors contributing significantly to the observed variation of $g_{1}$. The dominant role of $\Psi$ in determining $g$ under open conditions was confirmed by the fact that in the multiple regression analysis for open conditions, $\Psi$ was the sole independent variable which contributed significantly to the variation of $g$. Multiple regression analysis also confirmed the decreasing influence of $\Psi$ in determining $g$, with increasing shade. Under medium shade, $\Psi$ still had a significant, but lower than under open conditions, influence on $g_{1}$. In contrast, the influence of $\Psi$ was insignificant under full shade. On the other hand, the light intensity on the upper leaf surface had a significant contribution to determining $g_{1}$ under medium shade. This is understandable as light is a limiting factor under partially-shaded conditions. Therefore, increasing light intensity under such conditions would cause greater stomatal opening (i.e. higher $\left.g_{1}\right) .{ }^{10,11}$ Under fully-shaded conditions, in addition to light intensity, variation of leaf temperatures (both upper and lower surfaces) also had significant influences in determining $g$. This again is understandable because leaf temperature is determined by the leaf energy balance which incorporates the interaction between light intensity, transpiration, stomatal and boundary layer conductances of leaves and relative humidity of the surrounding air. ${ }^{2 !}$

This study provided important indications on the physiological ecology of different tree species within a forest community. The fact that the observations have been made under natural shade conditions on plants growing in the field rather than under artificial conditions, adds strength to the findings of this study and their physiological implications. Moreover, the definitions of different shade levels were validated by the results obtained which could be explained by the already-established principles of physiological ecology.

\section{Acknowledgement}

We gratefully acknowledge the technical assistance provided by P.R.S.D. Bandaranayake and K.B. Attanayake. 


\section{References}

1. Meidner H. \& Mansfield T.A. (1968). Physiology of stomata. McGraw-Hill, London.

2. Raschke K. (1975). Stomatal action. Annual Review of Plant Physiology 26: 309-340.

3. Burrows F.J. \& Milthorpe F.L. (1976). Stomatal conductance in the control of gas exchange. In: Water deficits and plant growth. vol. I. (Ed. T.T. Kozlowski) pp. 103-152. Academic Press, New York.

4. Davies W.J., Rhizopoulou S., Sanderson R., Taylor G., Metcalfe J.C. \& Zhang J. (1989). Water relations and growth of roots and leaves of woody plants. In: Biomass production by fast-growing trees. (Eds. J.S. Pereira \& J.J. Landsberg) pp. 13-36. Kluwer Academic Publishers, The Netherlands.

5. Pereira J.S. \& Pallardy S. (1989). Water stress limitations to tree productivity. In: Biomass production by fast-growing trees. (Eds. J.S. Pereira \& J.J. Landsberg) pp. 37-56. Kluwer Academic Publishers, The Netherlands.

6. Bazzaz F.A. (1991). Regeneration of tropical forests: physiological responses of pioneer and secondary species. In: Rain forest regeneration and management. (Eds. A. Gomez-Pompa, T.C. Whitmore \& M. Hadley) pp. 91-118.

7. Caldwell M.M. \& Pearcy R.W. (1994). Exploitation of environmental heterogeneity by plants. Academic Press, California, USA.

8. Bazzaz F.A. (1979). Physiological ecology of plant succession. Annual Review of Ecology and Systematics 10: 351-371.

9. Zeiger E., Farquhar G.D. \& Cowan I.R. (1987). Stomatal function. Stanford University Press, Stanford, USA. 503 pp.

10. Chazdon R.L. (1988). Sunflecks and their importance to forest understorey plants. Advances in Ecological Research 18: 1-63.

11. Pearcy R.W. (1990). Sunflecks and photosynthesis in plant canopies. Annual Review of Plant Physiology and Plant Molecular Biology 41: 421-453.

12. Zeiger E. (1983). The biology of stomatal guard cells. Annual Review of Plant Physiology 41: 441-475. 
13. Sharpe P.J.H., Wu H. \& Spence R.D. (1987). Stomatal mechanics. In: Stomatal function. (Eds. E. Zeiger, G.D. Farquhar \& I.R. Cowan) pp. 59-89. Stanford University Press, Stanford, USA.

14. Boyer J.S. (1985). Water transport. Annual Review of Plant Physiology 36: $473-516$.

15. Slatyer R.O. (1967). Plant water relationships. Academic Press, London.

16. Grime J.P. (1994). The role of plasticity in exploiting environmental heterogeneity. In: Exploitation of environmental heterogeneity by plants. (Eds. M.M. Caldwell \& R.W. Pearcy) pp. 1-19. Academic Press, California, USA.

17. Bazzaz F.A. (1996). Plants in changing environments. Cambridge University Press, Cambridge, UK. 320 pp.

18. De Costa W.A.J.M. \& Chandrapala A.G. (1997). Variation of stomatal conductance and its controlling factors of different species in a wet evergreen forest in the mid-country wet zone of Sri Lanka. In: Developments In forest science in 1997. Proceedings of the $3^{\text {rd }}$ Annual Forestry Symposium. (Ed. H.S. Amaraselzara). Department of Forestry and Environmental Science, University of Sri Jayewardenapura, Sri Lanka (In Press).

19. Panabokke C.R. (1996). Soils \& agro-ecological environments of Sri Lanka. Natural Resources, Energy and Science Authority of Sri Lanka. 220 pp.

20. Szeicz G., Monteith J.L. \& Dos Santos J.M. (1964). Tube solarimeter to measure radiation among plants. Journal of Applied Ecology 1: 169-174.

21. Scholander P.F., Hammel H.T., Bradstreet E.D. \& Hemmingsen E.A. (1965). Sap pressure in vascular plants. Negative hydrostatic pressure can be measured in plants. Science 148: 339-346.

22. Montgomery D.C. (1991). Design and analysis of experiments. $3^{\text {rd }}$ Edition. John Wiley \& Sons, New York. 649 pp.

23. Little T.M. \& Hills F.J. (1978). Agricultural experimentation: design and analysis. John Wiley and Sons, New York. 350 pp.

24. Jones H.G. (1987). Breeding for stomatal characters. In: Stomatal function. (Eds. E. Zeiger, G.D. Farquhar \& I.R. Cowan) pp. 431-443. Stanford University Press, Stanford, USA. 
25. Kramer P.J. (1983). Plant water relationships. Academic Press, New York, USA.

26. Mitloehner R. (1997). Using trees as indicators of environmental conditions by measuring their internal water status. Plant Research and Development 45: 33-50.

27. Harper J.L. (1977). The population biology of plants. Academic Press, London.

28. Bazzaz F.A. \& Wayne P.M. (1994). Coping with environmental heterogeneity: the physiological ecology of tree seedling regeneration across the gapunderstorey continuum In: Exploitation of environmental heterogeneity by plants. (Eds. M.M. Caldwell \& R.W. Pearcy) pp. 349-390. Academic Press, California, USA.

29. Jones H.G. (1992). Plants and microclimate: a quantitative approach to environmental plant physiology. $2^{\text {nd }}$ Edition. Cambridge University Press, UK. $428 \mathrm{pp}$. 